\title{
La profesión médica según la palabra de su Santidad Pio XII
}

La Universidad Nacional ha auspiciado la publicación de un folleto con todas las exposiciones del actual Pontífice, acerca de la medicina. En un país como el nuestro, en el que se derrochan ingentes cantidades de papel en divulgaciones sin mérito intrínseco ninguno, en folletones que si acaso sirven es para amontonarse como cosas inútiles, es algo consolador que las actuales directivas de la Universidad hayan visto la imperiosa necesidad de llevar a los médicos un acervo de enseñanzas de vigencia inmortal. Aquí llamámonos católicos creyendo con criminal ingenuidad que los deberes de un creyente se sintetizan en un culto meramente formal y externo. cuando los adversarios de la cristiandad se atanan por llenar sus arsenales con armas de sedicente cultura arrancada de los filones biológicos. Aqui. aun los que se llaman revolucionarios, no pasan de ser unos díscolos revoltosos que trabajan para el momento con olvido del pasado y menosprecio con los intereses de las generaciones por venir. Aquí prodíganse los títulos honoríticos cuando el calificativo de Maestro debe exigir ingentes esfuerzos para conseguirlo $y$ sin pares merecimientos para conservarlo. Por eso, aunque en las alocuciones de S. S. Pio XII. hay materia ilimite para muchos editoriales y comentarios, nos limitamos a reproducir estos conceptos:

"Es cierto que algunos rechazan como un absurdo y una quimera en la teoría y en la práctica, el concepto de una ciencia médica cristiana. Según ellos, no puede haber una medicina cristiana, de la manera que no hay una tisica o una química cristiana, teórica o práctica. El dominio de las ciencias exactas y experimentales - dicen ellos-va más allá del terreno religioso y ético. y por eso no conocen ni reconocen más que sus propias leyes inmanentes. ¡Curiosa. injustificada restricción del campo visual del problemal ¿No ven que lus objetos de estas ciencias no están aislados en el vacío, sino que 
forman parte del mundo universal; tienen un determinuur f........ grave, en el orden de los bienes y de los valores; están en contacto permanente con los objetos de las otras ciencias $y$, de manera particular, están bajo la ley de la inmanente y trascendente finalidad que los ata dentro de un todo ordenado? Concedamos, sin embargo. que cuando se trata de orientación cristiana de la ciencia, se mira no solamente a la ciencia en si misma cuanto a sus representantes $y$ cultivadores, en los que vive, se desarrolla y se manifiesta. También la tísica y la quimica, que los estudiosos y los profesionales de conciencia hacen servir para provecho $\mathrm{y}$ beneficio de cada uno de los individuos y de la sociedad, pueden resultar, en manos de hombres perversos, agentes - instrumentos de corrupción y de daño. Tanto más. pues, resulta claro que en la medicina. el interés supremo de la verdad y del bien se opone a una pretendida libertad objetiva $y$ subjetiva de aquellas múltiples relaciones y vinculos que la mantienen en el orden general.

No querriamos, finalmente, dejar de decir una palabra sobre la obligación que el médico tiene, no solamente de poseer una sólida cultura científica. sino también de continuar siempre desarrollando y completando sus conocimientos y sus aptitudes profesionales. Se trata aquí, de un deber moral en sentido estricto, de un vínculo qua liga la conciencia ante Dios, porque se refiere a una actividad que toca de cerca a los bienes esenciales del individuo y de la sociedad. Este vinculo trae consigo: para el estudiante de medicina durante el tiempo de su formación universitaria, la obligación de dedicarse seriamente al estudio para adquirir los conocimientos teóricos requeridos y la habilidad práctica necesaria en su aplicación: para el profesor universitario, el deber de enseñar y de comunicar a los alumnos una cosa y otra del mejor modo posible, y de no conceder a nadie el certificado de capacidad profesional sin haberse. previamente, asegurado de ello con un concienzudo y profundo examen. Obrar de otra manera sería cometer una grave culpa mortal, porque expondria la salud privada y pública a peligros serios $y$ daños incalculables; para el médico que ya ejercita su profesión, la obligación de estar al corriente del desarrollo y de los progresos de la ciencia médica: mediante la lectura de obras y de revistas científicas, la participación en congresos y cursos académicos. las conversaciones con los colegas y las consultas con los profesores de la Facultades de Medicina. Este cuidado constante de perfeccionarse obliga al médico, que ejercita la profesión, en cuanto que prácticamente le es posible y es solicitado por el bien de los enfermos y de la comunidad . 